\title{
Pre-pandemic cognitive function and COVID-19 mortality: prospective cohort study
}

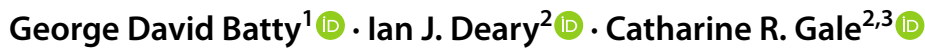

Received: 17 February 2021 / Accepted: 25 March 2021 / Published online: 24 April 2021

(c) The Author(s) 2021

\begin{abstract}
Poorer performance on standard tests of pre-morbid cognitive function is related to an elevated risk of death from lower respiratory tract infections but the link with coronavirus (COVID-19) mortality is untested. Participants in UK Biobank, aged 40 to 69 years at study induction (2006-10), were administered a reaction time test, an indicator of information processing speed, and also had their verbal-numeric reasoning assessed. Between April 1st and September 23rd 2020 there were 388 registry-confirmed deaths (138 women) ascribed to COVID-19 in 494,932 individuals (269,602 women) with a reaction time test result, and 125 such deaths (38 women) in the subgroup of 180,198 people (97,794 women) with data on verbalnumeric reasoning. In analyses adjusted for age, sex, and ethnicity, a one standard deviation slower reaction time was related to a higher rate of death from COVID-19 (hazard ratio; 95\% confidence interval: $1.18 ; 1.09,1.28$ ), as was a one standard deviation disadvantage on the verbal-numeric reasoning test $(1.32 ; 1.09,1.59)$. While there was some attenuation in these relationships after adjustment for additional covariates which included socio-economic status and lifestyle factors, the two pre-pandemic indicators of cognitive function continued to be related to COVID-19 mortality.
\end{abstract}

Keywords COVID-19 · Cognitive function · Cohort

\section{Introduction}

Cognitive function-also referred to as mental ability or intelligence-refers to psychological functions that involve the storage, selection, manipulation, and organisation of information, and the planning of actions. Evidence from well-characterised cohort studies suggest that lower scores on standard tests of cognition are linked to elevated rates of premature mortality and cardiovascular disease [1]. Similar

George David Batty

david.batty@ucl.ac.uk

Ian J. Deary

i.deary@ed.ac.uk

Catharine R. Gale

crg@mrc.soton.ac.uk

1 Department of Epidemiology and Public Health, University College London, 1-19 Torrington Place, London WC1E 6BT, UK

2 Lothian Birth Cohorts, Department of Psychology, University of Edinburgh, Edinburgh, UK

3 Medical Research Council Lifecourse Epidemiology Unit, University of Southampton, Southampton, UK inverse relations have recently been reported for cognition and death from respiratory infection, comprising pneumonia and influenza [2]. Various explanations have been advanced, including the observation that people with higher cognitive ability are better equipped to obtain, process, and respond to disease prevention advice, as well as having healthier behaviours which include a lower prevalence of cigarette smoking [3], itself a risk factor for pneumonia [4].

These observations inevitably raise the possibility that individuals with lower mental ability may experience a higher burden of COVID-19. In a recent examination of primary care records, relative to an unaffected group, people with intellectual disability experienced around ten times the risk of death ascribed to COVID-19 and five times the risk of hospitalisation, even after adjustment for age and other co-morbidities [5]. In a field-based cohort study of a non-disabled population, of a range of baseline psychosocial factors, cognitive function was the most strongly predictive of hospitalisation for COVID-19, whereby a doubling of disease risk was apparent in the lowest scoring group [6]. With the pandemic evolving since we published those analyses using UK Biobank [6], there is now a sufficiently high number of deaths in this study to examine if similar 
results are apparent for pre-pandemic cognitive function and COVID-19 mortality-an association which, to the best of our knowledge, has yet to be tested.

\section{Methods}

Between 2006 and 2010, baseline data were collected in the UK Biobank, a prospective cohort study. Conducted across 22 research assessment centres, a total of 502,655 individuals aged 40 to 69 years participated (response 5.5\%) [7]. Ethical approvals were received from the North-West Multicentre Research Ethics Committee. Data are publicly available upon application (https://www.ukbiobank.ac.uk/), and the present analyses of anonymised data did not require further ethical permissions.

\section{Assessment of cognitive function}

We use two tests of cognitive function as administered at baseline. Verbal and numeric ('verbal-numeric') reasoning was assessed using a computerized 13-item multiple-choice test with a two-minute time limit. The score derived was the number of correct answers. This test was introduced during the baseline assessment period; therefore, data are available for a subset of study members only $(\mathrm{N}=180,914)$. Reaction time, which captures speed of information processing, is a knowledge-reduced indicator of cognition. Measured in the present study using a computerized Go/No-Go "Snap"type game $(\mathrm{N}=496,882)$, participants were presented with electronic images of two cards. If symbols on the cards were identical, participants were instructed to immediately push the button-box using their dominant hand. The first five pairs were used as a practice with the remaining seven pairs, containing four identical cards, forming the assessment. Reaction time score was the mean time (milliseconds) taken to depress the button after each of these four matching pairs was presented. Reaction time correlates with cognitive tests that involve complex reasoning and knowledge such that people with higher cognitive ability tend to have faster reaction times [8].

\section{Assessment of confounding factors}

Covariates were also assessed at baseline. Socioeconomic status was quantified using self-reported educational qualifications (degree, other qualifications, no qualifications), occupational classification based on current job, and the Townsend index of neighbourhood deprivation (higher scores denote greater disadvantage). Ethnicity was categorised as White, Asian, Black, Chinese, Mixed, or 'other' ethnic group. Vascular or heart problems, diabetes, chronic bronchitis or emphysema, and asthma, were based on self-report of a physician diagnosis. Hypertension was defined as systolic/diastolic blood pressure $\geq 140 / 90 \mathrm{mmHg}$ and/or self-reported use of antihypertensive medication. Study members were also asked whether they had ever been under the care of a psychiatrist for any mental health problem. C-reactive protein, glycated haemoglobin, and highdensity lipoprotein cholesterol concentrations were based on assays of non-fasting venous blood. Height, weight-from which body mass index was computed-and forced expiratory volume in one second were measured using standard protocols. Cigarette smoking, physical activity, and alcohol consumption were assessed using standard enquiries. Study members were linked to national mortality records and death from COVID-19, our outcome of interest, was denoted by the emergency ICD-10 code U07.1 (COVID-19, virus identified).

\section{Statistical analyses}

To summarise the relation between cognition and mortality we used Cox regression to compute hazard ratios with accompanying $95 \%$ confidence intervals. In these analyses we calculated effect estimates for tertiles of scores for both the test of verbal-numeric reasoning $(<4$ [most disadvantaged], 5-6, $\geq 7)$ and reaction time $(\leq 499 \mathrm{~ms}$, $500-581, \geq 582$ [most disadvantaged]). We also computed hazard ratios for a unit (standard deviation) disadvantage in score for verbal numeric reasoning (per 2.16 point decrease) and reaction time (per $118.2 \mathrm{~ms}$ increase). The most basic analyses were adjusted for known COVID-19 risk factors (age, sex, and ethnicity). Retaining these covariates, we then explored the impact of separately controlling for socioeconomic circumstances, existing medical conditions, lifestyle factors, and biological indices.

\section{Results}

In 502,655 study members (273,472 women), 404 deaths (145 in women) were ascribed to COVID-19 between April 1 st and September 23rd 2020. In Table 1, in age-, sex- and ethnicity-adjusted analyses, we show, individually, the relation of the covariates and cognitive data with death from COVID-19. Twenty covariates were related to a higher risk of death from COVID-19 in these minimally-adjusted analyses; only the point estimate for regular intake of alcohol and asthma did not achieve statistical significance at conventional levels. Thus, there was a raised risk of COVID19 death in people who were older, male, of ethnic minority ancestry, and socioeconomically disadvantaged. Those study members who smoked, reported less physical activity, and had higher body mass index, those with extant illness at baseline, and those with unfavourable levels of known 
Table 1 Cognitive function and covariates at baseline (2006-2010) according to death from COVID-19 (2020)

\begin{tabular}{|c|c|c|c|c|}
\hline & \multicolumn{2}{|l|}{ COVID-19 mortality } & \multirow[t]{2}{*}{$p$ value } & \multirow[t]{2}{*}{ Hazard ratios $(95 \% \mathrm{CI})$} \\
\hline & $\begin{array}{l}\text { Yes } \\
(\mathrm{n}=404)\end{array}$ & $\begin{array}{l}\text { No } \\
(\mathrm{n}=502,251)\end{array}$ & & \\
\hline \multicolumn{5}{|l|}{ Demographic factors } \\
\hline Age, year, mean (SD) & $62.7(6.03)$ & $56.5(8.09)$ & $<0.0001$ & $3.07(2.67,3.53)$ \\
\hline Female, N (\%) & $145(35.9)$ & $273,327(54.4)$ & $<0.0001$ & $0.48(0.38,0.59)$ \\
\hline Non-white ethnicity & $37(9.27)$ & $26,997(5.41)$ & 0.001 & $3.75(2.67,5.27)$ \\
\hline \multicolumn{5}{|l|}{ Comorbidities } \\
\hline Vascular or heart disease, $\mathrm{N}(\%)$ & $216(54.3)$ & $149,139(29.8)$ & $<0.0001$ & $1.79(1.46,2.19)$ \\
\hline Hypertension, N (\%) & $313(79.9)$ & $282,324(57.2)$ & $<0.0001$ & $1.70(1.32,2.19)$ \\
\hline Diabetes, N (\%) & $63(15.8)$ & $26,345(5.27)$ & $<0.0001$ & $2.31(1.75,3.06)$ \\
\hline Chronic bronchitis or emphysema, N (\%) & $18(4.46)$ & $8,334(1.66)$ & $<0.0001$ & $2.37(1.47,3.80)$ \\
\hline Asthma, N (\%) & $34(8.42)$ & $57,879(11.5)$ & 0.050 & $0.80(0.56 .1 .14)$ \\
\hline Mental health—Psychiatric consultation, N (\%) & $56(14.1)$ & $57,625(11.6)$ & 0.117 & $1.42(1.07,1.88)$ \\
\hline \multicolumn{5}{|l|}{ Lifestyle factors } \\
\hline Current smoker, $\mathrm{N}(\%)$ & $50(12.6)$ & $52,580(10.5)$ & $<0.0001$ & $1.88(1.37,2.59)$ \\
\hline No physical activity, N (\%) & $55(14.0)$ & $32,804(6.63)$ & $<0.0001$ & $2.54(1.90,3.40)$ \\
\hline Drinks alcohol daily/almost daily, N (\%) & $85(21.3)$ & $101,707(20.3)$ & 0.641 & $0.88(0.69,1.12)$ \\
\hline Body mass index, $\mathrm{kg} / \mathrm{m}^{2}$, mean (SD) & $29.7(5.83)$ & $27.4(4.80)$ & $<0.0001$ & $1.51(1.39,1.65)$ \\
\hline \multicolumn{5}{|l|}{ Biomarkers } \\
\hline Lung function, L, mean (SD) & $2.53(0.87)$ & $2.81(0.80)$ & $<0.0001$ & $0.69(0.60,0.80)$ \\
\hline C-reactive protein, $\mathrm{mg} / \mathrm{L}$, median (IQR) & $1.72(0.83,3.51)$ & $1.26(0.63,2.49)$ & 0.0001 & $1.26(1.12,1.41)$ \\
\hline High-density lipoprotein, mmol/L, median (IQR) & $1.26(1.09,1.52)$ & $1.40(1.17,1.67)$ & 0.0001 & $0.79(0.69,0.90)$ \\
\hline HbA1C, mmol/mol, median (IQR) & $36.7(33.8,40.7)$ & $35.2(32.8,37.9)$ & 0.0001 & $1.25(1.16,1.35)$ \\
\hline \multicolumn{5}{|l|}{ Socioeconomic factors } \\
\hline No university education, N (\%) & $310(80.7)$ & $330,988(67.3)$ & $<0.0001$ & $1.75(1.35,2.26)$ \\
\hline Neighbourhood deprivation score, median (IQR) & $-0.887(-3.04,-2.48)$ & $-2.14(-3.64,0.55)$ & 0.0001 & $1.45(1.33,1.59)$ \\
\hline Personal service, sales occupations etc., N (\%) & $54(27.8)$ & $66,160(19.0)$ & 0.002 & $1.57(1.15,2.16)$ \\
\hline \multicolumn{5}{|l|}{ Cognitive factors } \\
\hline Verbal-numeric reasoning, mean (SD) & $5.32(2.20)$ & $6.02(2.16)$ & 0.0002 & $1.32(1.09,1.59)$ \\
\hline Reaction time, msec, mean (SD) & $606.1(136.4)$ & $559.9(118.2)$ & $<0.0001$ & $1.18(1.09,1.28)$ \\
\hline
\end{tabular}

Hazard ratios are adjusted for age, sex, and ethnicity and expressed per category, or per SD increase for continuous variables (except for reasoning which is expressed per SD decrease [disadvantage]). The maximum analytical sample of 502,655 people was lower in selected analyses owing to missing data

cardiovascular disease biomarkers-lower lung function, higher systemic inflammation, lower high-density lipoprotein, and higher glycated haemoglobin-also experienced elevated rates of COVID-19 mortality.

In analyses adjusted for age, sex, and ethnicity, individuals with lower verbal-numeric reasoning scores had a higher risk of death ascribed to COVID-19 (hazard ratio per SD disadvantage; $95 \%$ confidence interval: $1.32 ; 1.09,1.59$ ) (Tables 1 and 2). Whereas adjusting for markers of socioeconomic position and biological factors had little impact on these effect estimates, adding co-morbidity to the multivariable model led to some attenuation $(1.25 ; 1.04,1.52)$. The greatest degree of attenuation, however, was evident after adjusting for lifestyle indices (1.16; 0.96, 1.41) which included smoking and body weight.
Associations with COVID-19 mortality are also shown by tertiles of the cognitive exposures in Table 2. In minimallyadjusted analyses (age, sex, ethnicity), relative to the highest performing tertile of verbal-numeric reasoning, those people in the lowest-scoring group experienced a doubling in the rate of death from COVID-19 (2.04; 1.30, 3.20). There was also evidence of a dose-response effect such that the intermediate cognition group $(1.35 ; 0.86,2.14)$ experienced an intermediate level of risk ( $P$ for trend: 0.002). Covariate control had little impact on these results, the exception being lifestyle factors. In those analyses, although rates of COVID-19 mortality were still associated with around a 50\% increase risk in the lowest cognition-scoring group (1.52; $0.95,2.43)$, statistical significance at conventional levels was lost. 
Table 2 Hazard ratios (95\% confidence intervals) for the association of measures of baseline cognitive function (2006-2010) with death from COVID-19 (2020)

\begin{tabular}{|c|c|c|c|c|c|c|}
\hline & $\begin{array}{l}\text { Adjusted for age, } \\
\text { sex, and ethnicity }\end{array}$ & $\begin{array}{l}\text { Adjusted for age, } \\
\text { sex, ethnicity, and } \\
\text { comorbidity }\end{array}$ & $\begin{array}{l}\text { Adjusted for age, } \\
\text { sex, ethnicity, and } \\
\text { markers of socio- } \\
\text { economic status }\end{array}$ & $\begin{array}{l}\text { Adjusted for age, } \\
\text { sex, ethnicity, and } \\
\text { lifestyle factors }\end{array}$ & $\begin{array}{l}\text { Adjusted for age, } \\
\text { sex, ethnicity, and } \\
\text { biological factors }\end{array}$ & $\begin{array}{l}\text { Adjusted for all } \\
\text { covariates }\end{array}$ \\
\hline \multicolumn{7}{|c|}{ Verbal-numeric reasoning } \\
\hline $\begin{array}{l}\text { Cases/Number at } \\
\text { risk }\end{array}$ & $125 / 180,198$ & $123 / 177,361$ & $90 / 145,975$ & $119 / 177,545$ & $77 / 126,190$ & $58 / 101,731$ \\
\hline $\begin{array}{l}1 \text { (most disadvan- } \\
\text { taged) }\end{array}$ & $2.04(1.30,3.20)$ & $1.86(1.18,2.93)$ & $2.22(1.26,3.94)$ & $1.52(0.95,2.43)$ & $2.32(1.30,4.14)$ & $2.33(1.16,4.69)$ \\
\hline 2 & $1.35(0.86,2.14)$ & $1.29(0.81,2.03)$ & $1.34(0.78,231)$ & $1.27(0.80,2.01)$ & $1.62(0.90,1.89)$ & $1.39(0.73,2.67)$ \\
\hline 3 & 1.0 (reference) & 1.0 & 1.0 & 1.0 & 1.0 & 1.0 \\
\hline$P$ for trend & 0.002 & 0.007 & 0.006 & 0.082 & 0.004 & 0.019 \\
\hline $\begin{array}{l}\text { Per SD disadvan- } \\
\text { tage }\end{array}$ & $1.32(1.09,1.59)$ & $1.25(1.04,1.52)$ & $1.31(1.02,1.67)$ & $1.16(0.96,1.41)$ & $1.29(1.01,1.64)$ & $1.27(0.94,1.71)$ \\
\hline \multicolumn{7}{|l|}{ Reaction time } \\
\hline $\begin{array}{l}\text { Cases/Number at } \\
\text { risk }\end{array}$ & $388 / 494,932$ & $378 / 483,785$ & $182 / 339,977$ & $373 / 484,832$ & $250 / 352,096$ & $122 / 243,954$ \\
\hline 1 & 1.0 (reference) & 1.0 & 1.0 & 1.0 & 1.0 & 1.0 \\
\hline 2 & $0.97(0.73,1.30)$ & $0.92(0.69,1.24)$ & $1.01(0.67,1.54)$ & $0.94(0.70,1.27)$ & $0.90(0.62,1.30)$ & $0.84(0.50,1.43)$ \\
\hline $\begin{array}{l}3 \text { (most disadvan- } \\
\text { taged) }\end{array}$ & $1.50(1.15,1.95)$ & $1.40(1.07,1.83)$ & $1.66(1.13,2.44)$ & $1.35(1.03,1.77)$ & $1.50(1.08,2.09)$ & $1.75(1.10,2.77)$ \\
\hline$P$ for trend & 0.001 & 0.003 & 0.004 & 0.009 & 0.003 & 0.006 \\
\hline $\begin{array}{l}\text { Per SD disadvan- } \\
\text { tage }\end{array}$ & $1.18(1.09,1.28)$ & $1.16(1.07,1.27)$ & $1.21(1.07,1.37)$ & $1.15(1.06,1.25)$ & $1.19(1.07,1.31)$ & $1.22(1.04,1.43)$ \\
\hline
\end{tabular}

Comorbidities: diagnoses of vascular or heart disease, diabetes, chronic bronchitis or emphysema, asthma, hypertension, and mental illness

Socioeconomic status (SES): educational attainment, occupational classification, and area deprivation. Lifestyle factors: body mass index, smoking status, alcohol intake, and physical activity. Biomarkers: Forced expiratory volume in the first second, and blood concentrations of C-reactive protein, glycated haemoglobin, and high-density lipoprotein

Slower responders to the reaction time test had an elevated risk of death from the disease (hazard ratio per SD disadvantage: $1.18 ; 1.09,1.28$ ) (Tables 1 and 2). In contrast to the analyses for verbal-numeric reasoning, there was less attenuation of estimates after controlling for the same covariates (Table 2). Adjustment for lifestyle factors again resulted in the greatest attenuation of the cognition-mortality gradient but this was modest $(1.15 ; 1.06,1.25)$, and statistical significance at conventional levels was retained owing to the larger analytical sample in the reaction time analyses. Unlike the analyses of verbal-numeric reasoning, however, when the results were analysed by tertiles, there appeared to be a threshold effect in each model: only people in the slowest reaction time tertile had elevated risk; the hazard ratio in the intermediate group approximated 1. Collective control for all measured confounding factors did not impact further on the pattern of the relationship for death from COVID-19 and our two indicators of cognitive function.

Lastly, given the known correlation for education and verbal-numeric reasoning $(\mathrm{r}=0.40, p<0.0001, \mathrm{~N}=178,908$ in the present data), we conducted separate adjustment for education, one of three indicators of socioeconomic status used herein (Table 1a, appendix). Controlling for education had a marginal attenuating effect on the strength of the cognition-COVID-19 death association, whereas the addition of the other socioeconomic factors of area deprivation and occupational classification led to positive confounding such that the magnitude of categorical effects increased somewhat. It is also the case, however, that, owing to some missing data for occupation, the apparent difference in strength of the association may at least partly reflect differences in sample size. With reaction time being a knowledgereduced measure of cognition, its relationship with education $(\mathrm{r}=0.15, p<0.0001, \mathrm{~N}=487,993)$ was weaker than for verbal-numeric reasoning.

\section{Discussion}

Our main finding was that, net of several covariates, poorer scores on two tests of cognition-verbal-numeric reasoning and reaction time-were associated with a higher risk of death from COVID-19. Patterns of attenuation were similar for both exposures such that the greater impact was apparent 
after control for lifestyle factors, whereas physiological indices had little if any attenuating effect. We also replicated known risk factors for death from COVID-19-being older, male, from an ethnic minority, socioeconomically disadvantaged, and having an extant somatic medical condition have been repeatedly linked with poor prognosis in COVID-19 patients in China [9] and elsewhere. Similarly, both verbalnumeric reasoning (hazard ratio per SD disadvantage; $95 \%$ confidence interval: $1.17 ; 1.14,1.20)$ and reaction time $(1.15 ; 1.14,1.16)$ demonstrated the expected associations $[1,10]$ with all-cause mortality $(31,187$ deaths in the full cohort) (Table 1b, appendix). The raised risk of COVID19 mortality seen in people with the most disadvantaged scores for reaction time - as described, a knowledge-reduced measure of cognition - corroborates the results for verbalnumeric reasoning which is more closely linked to education. It is also the case that the magnitude of association for scores on both tests were little attenuated after taking into account educational attainment.

\section{Plausible mechanisms}

There has been a deluge of health advice in the current pandemic during an era when news outlets and social media platforms have never been more ubiquitous. Preventative information has ranged from the simple and practical to the complex, contradictory, false, and fraudulent. In order to diminish their risk of the infection, the population has to acquire, synthesise, and deploy this information but the ability to do so seems to vary by levels of health literacy [11] just as it may for its close correlate, cognitive function.

\section{Potential implications}

People with low cognition scores may be conceptualised as being a vulnerable group. As well as seemingly having an elevated risk of death from COVID-19 in the present study, evidence suggests that people with lower ability report being less likely to take up the offer of a vaccine [12]. Lower cognitive function may therefore represent a dual burden, as is perhaps also the case for ethnic minority groups and socioeconomically disadvantaged communities [6]. Further, given the current overabundance of health opinion, governments and public health agencies have an increased responsibility to provide simple and practical advice. This has not always been so in the UK during the pandemic.

Lifestyle factors explained the greatest portion of the association between cognition and death due to COVID19. As discussed, there is good evidence that people with lower ability have less favourable health behaviours-they are more likely to smoke, be physically inactive, have a less prudent diet, and drink heavily [3, 13-15]. The skills captured by cognition tests, such as comprehension and reasoning, may be important in the successful management of health behaviours. Behavioural modification advice could therefore be recalibrated to make it more suitable for people with lower ability.

\section{Study strengths and weaknesses}

The strengths of our study include the well-characterised nature of the sample and the full coverage of the population for cause of death. Our study also has some weaknesses. With the present sample not being representative of the general UK population, death rates from leading causes and the prevalence of reported risk factors are known to be underestimates of those apparent in less select groups [7]; the same is likely to be the case for COVID-19 deaths. This notwithstanding, there is evidence that, for major causes of death, risk factor associations are externally valid [7]. Secondly, levels of our baseline data-exposures and covariates-will vary in the period between study induction in UK Biobank and the present pandemic. This is a perennial issue in cohort studies and one we were able to investigate using data from a resurveys that took place in a sub-sample 4 to 8 years after baseline examination. Analyses revealed moderate and similar levels of stability for verbal-numeric reasoning $(\mathrm{r}=0.63, p<0.001, \mathrm{~N}=9689)$ and reaction time $(\mathrm{r}=0.49, p<0.001, \mathrm{~N}=28,810)$ relative to key covariates such as such as cigarette smoking $(0.60, p<0.001$, $\mathrm{N}=31,037)$, blood pressure $(0.65, p<0.001, \mathrm{~N}=19,772)$, and diabetes $(\mathrm{r}=0.63, p<0.001, \mathrm{~N}=31,037)$. Most observational studies in the context of chronic disease epidemiology use a single baseline measurement of the exposure and relate it to disease onset. In the few analyses incorporating a repeat measurement, risk factor-disease associations appear to be strengthened [16] and we would anticipate the same for cognition. Lastly, as is inevitable, unmeasured confounding factors may offer additional explanatory power in this observational study.

In conclusion, in the present study, poorer performance on two pre-pandemic indicators of cognitive function, including reaction time, a knowledge-reduced measure, was related to death ascribed to COVID-19.

Supplementary Information The online version contains supplementary material available at https://doi.org/10.1007/s10654-021-00743-7.

Acknowledgements We thank UK Biobank study members for their generosity in participating.

Funding GDB is supported by the UK Medical Research Council (MR/ P023444/1) and the US National Institute on Aging (1R56AG05251901; 1R01AG052519-01A1); and IJD by the UK Medical Research Council (MR/R024065/1), UK Economic and Social Research Council (ES/S015604/1), and US National Institute on Aging, US (1R01AG054628-01A1). These funders, who provided no direct financial or material support for the work, had no role in study design, 
data collection, data analysis, data interpretation, or report preparation. Access to data: Data from UK Biobank (http://www.ukbiobank. ac.uk/) are available to bona fide researchers upon application. Part of this research has been conducted using the UK Biobank Resource under Application 10279.

Open Access This article is licensed under a Creative Commons Attribution 4.0 International License, which permits use, sharing, adaptation, distribution and reproduction in any medium or format, as long as you give appropriate credit to the original author(s) and the source, provide a link to the Creative Commons licence, and indicate if changes were made. The images or other third party material in this article are included in the article's Creative Commons licence, unless indicated otherwise in a credit line to the material. If material is not included in the article's Creative Commons licence and your intended use is not permitted by statutory regulation or exceeds the permitted use, you will need to obtain permission directly from the copyright holder. To view a copy of this licence, visit http://creativecommons.org/licenses/by/4.0/.

\section{References}

1. Calvin CM, Batty GD, Der G, et al. Childhood intelligence in relation to major causes of death in 68 year follow-up: prospective population study. BMJ. 2017;357:j2708.

2. Gale CR, Deary IJ, Batty GD. Cognitive ability and risk of death from lower respiratory tract infection: findings from UK Biobank. Sci Rep. 2019;9(1):1342.

3. Batty GD, Deary IJ, MacIntyre S. Childhood IQ in relation to risk factors for premature mortality in middle-aged persons: the Aberdeen Children of the 1950s study. J Epidemiol Community Health. 2007;61(3):241-7.

4. Baik I, Curhan GC, Rimm EB, Bendich A, Willett WC, Fawzi WW. A prospective study of age and lifestyle factors in relation to community-acquired pneumonia in US men and women. Arch Intern Med. 2000;160(20):3082-8.

5. Clift AK, Coupland CAC, Keogh RH, Hemingway H, HippisleyCox J. COVID-19 mortality risk in down syndrome: results from a Cohort Study Of 8 Million Adults. Ann Intern Med. 2020.

6. Batty GD, Deary IJ, Luciano M, Altschul DM, Kivimaki M, Gale CR. Psychosocial factors and hospitalisations for COVID-19: Prospective cohort study based on a community sample. Brain Behav Immun. 2020;89:569-78.
7. Batty GD, Gale CR, Kivimaki M, Deary IJ, Bell S. Comparison of risk factor associations in UK Biobank against representative, general population based studies with conventional response rates: prospective cohort study and individual participant meta-analysis. BMJ. 2020;368:m131.

8. Deary IJ, Der G, Ford G. Reaction times and intelligence differences: a population-based cohort study. Intelligence. 2001;29:389-99.

9. Wu C, Chen X, Cai Y, et al. risk factors associated with acute respiratory distress syndrome and death in patients with coronavirus disease 2019 Pneumonia in Wuhan, China. JAMA Intern Med. 2020.

10. Hagger-Johnson G, Deary IJ, Davies CA, Weiss A, Batty GD. Reaction time and mortality from the major causes of death: the NHANES-III study. PLoS ONE. 2014;9(1):e82959.

11. Wolf MS, Serper M, Opsasnick L, et al. Awareness, attitudes, and actions related to COVID-19 among adults with chronic conditions at the onset of the U.S. Outbreak: a cross-sectional survey. Ann Internal Med. 2020.

12. Murphy J, Vallières F, Bentall RP, et al. Psychological characteristics associated with COVID-19 vaccine hesitancy and resistance in Ireland and the United Kingdom. Nat Commun. 2021;12(1):29.

13. Batty GD, Deary IJ, Schoon I, Gale CR. Childhood mental ability in relation to food intake and physical activity in adulthood: the 1970 British Cohort Study. Pediatrics. 2007;119(1):e38-45.

14. Batty GD, Deary IJ, MacIntyre S. Childhood IQ and life course socioeconomic position in relation to alcohol induced hangovers in adulthood: the Aberdeen children of the 1950s study. J Epidemiol Community Health. 2006;60(10):872-4.

15. Batty GD, Deary IJ, Schoon I, Gale CR. Mental ability across childhood in relation to risk factors for premature mortality in adult life: the 1970 British Cohort Study. J Epidemiol Community Health. 2007;61(11):997-1003.

16. Clarke R, Shipley M, Lewington S, et al. Underestimation of risk associations due to regression dilution in long-term follow-up of prospective studies. Am J Epidemiol. 1999;150(4):341-53.

Publisher's Note Springer Nature remains neutral with regard to jurisdictional claims in published maps and institutional affiliations. 